\title{
Grain refinement in an Al-Mg-Sc alloy: Equal channel angular pressing versus friction-stir processing
}

\author{
Vladislav Kulitskiy ${ }^{\mathrm{a}, *}$, Sergey Malopheyev ${ }^{\mathrm{a}}$, Sergey Mironov ${ }^{\mathrm{b}}$, Rustam Kaibyshev ${ }^{\mathrm{a}}$ \\ a Laboratory of the Mechanical Properties of Nanoscale Materials and Superalloys, Belgorod State University, Pobeda 85, Belgorod 308015, Russia \\ ${ }^{\mathrm{b}}$ Department of Materials Processing, Graduate School of Engineering, Tohoku University, 6-6-02 Aramaki-aza-Aoba, Sendai 980-8579, Japan
}

\section{A R T I C L E I N F O}

\section{Article history:}

Received 11 April 2016

Received in revised form

3 August 2016

Accepted 5 August 2016

Available online 6 August 2016

Keywords:

Aluminum alloy

Equal channel angular pressing

Friction-stir processing

Ultrafine-grained microstructure

Microstructure-properties relationship

\begin{abstract}
A B S T R A C T
The efficiencies of equal channel angular pressing (ECAP) and friction-stir processing (FSP) for grain refinement in an Al-Mg-Sc alloy were directly compared. Based on detailed microstructural examinations, microstructure-strength relationships for both processing techniques were quantified.

In contrast to ECAP, the fine-grained material produced by FSP was found to be characterized by a coarser grain- and dispersoid size, lower dislocation density, more irregular texture, higher high-angle boundary fraction and lower strength. The comparatively low efficiency of FSP for grain refinement and enhancement of strength was attributed to the relatively high processing temperature and the relatively low cooling speed.
\end{abstract}

(c) 2016 Elsevier B.V. All rights reserved.

\section{Introduction}

Al-Mg-Sc alloys were developed as a new class of high-performance materials for application in the aerospace industry [1]. Minor additions of Sc to Al-Mg alloys lead to the precipitation of well-distributed nano-scale coherent $\mathrm{Al}_{3} \mathrm{Sc}$ dispersoids, which imparts a significant strengthening effect and promotes excellent thermal stability [2].

The superior properties of these materials may further be improved through the formation of an ultra-fine grained (UFG) microstructure. Equal-channel angular pressing (ECAP) is often believed to be one of the most effective approaches for this purpose $[3,4]$. In this technique, excellent grain-refinement efficiency is combined with simplicity and the ability to produce the UFG structure in large-scale billets. This makes ECAP attractive for commercial applications. In Al-Mg-Sc alloys, ECAP has been well established to be very effective for grain refinement and, consequently, property enhancement [e.g., 5-9].

Recently, a new microstructural refinement technique, named friction-stir processing (FSP), has been introduced [10]. Shortly after its invention, FSP has conclusively demonstrated its excellent

\footnotetext{
* Corresponding author.

E-mail addresses: kulitskiy@bsu.edu.ru (V. Kulitskiy), malofeev@bsu.edu.ru (S. Malopheyev),

smironov@material.tohoku.ac.jp (S. Mironov),

rustam_kaibyshev@bsu.edu.ru (R. Kaibyshev).
}

grain-refinement ability in various structural materials, including Al-Mg-Sc alloys [e.g., 11-18]. This method is relatively simple and fast, and it is believed to be suitable for commercial production.

In this work, the efficiencies of ECAP and FSP for grain refinement in an Al-Mg-Sc alloy were directly compared with each other. To this end, several ECAP and FSP trials were performed over a wide temperature range. The produced microstructures were characterized using high-resolution electron backscatter diffraction (EBSD) and transmission electron microscopy (TEM). Based on a detailed microstructural examination, the strengthening mechanisms contributing to the room temperature yield strength were quantified.

\section{Experiments}

A commercial alloy with a chemical composition of Al-5.4Mg$0.37 \mathrm{Mn}-0.2 \mathrm{Sc}-0.09 \mathrm{Zr}-0.29 \mathrm{Ti}-0.07 \mathrm{Fe}-0.04 \mathrm{Si}$ (in wt\%) was produced by semi-continuous casting. The obtained ingot was homogenized at $360{ }^{\circ} \mathrm{C}$ for $8 \mathrm{~h}$ and then extruded at $380^{\circ} \mathrm{C}$ with an area reduction of $75 \%$. This material condition was denoted as the initial material throughout this work.

For ECAP, rods with a square cross-section of $20 \times 20 \mathrm{~mm}^{2}$ and $100 \mathrm{~mm}$ in length were machined from the central part of the extruded billet parallel to the extrusion axis. These samples were subjected to ECAP using an isothermal die with a $90^{\circ}$ square channel and a pressing speed of $\sim 5 \mathrm{~mm} / \mathrm{s}$. To facilitate ECAP, back 
pressure was used. To investigate the effect of temperature on grain-refinement efficiency, ECAP was conducted at four different temperatures of $300,350,400$ and $450^{\circ} \mathrm{C}$, respectively. In all cases, the material was pressed for a total of 12 passes, to produce a total true strain of $\sim 12$ using processing route $B_{c}$. In this route, the samples were rotated by $90^{\circ}$ in the same sense around pressing direction between each consecutive pass [3]. Following ECAP, the material was immediately quenched in water. The principal directions of the ECAP geometry were denoted throughout as the pressing direction (PD), normal direction (ND) and transverse direction (TD) [3].

For FSP, 4.3-mm-thick sheets were cut from the extruded material and butt-welded transverse to the extrusion direction. The welding tool was fabricated from a tool steel and consisted of a shoulder with a diameter of $20 \mathrm{~mm}$ and an M5 cylindrical pin of $3.1 \mathrm{~mm}$ in length. FSP was performed using an AccuStir 1004 machine. During FSP, the tool was tilted by $2.5^{\circ}$ from the sheet normal such that the rear of the tool was lower than the front. To provide different temperature conditions for grain refinement, FSP was conducted at four different tool rotational speeds of 350,500, 650 and $800 \mathrm{rpm}$, respectively, whereas the tool travel speed was kept constant at $75 \mathrm{~mm} / \mathrm{min}$. The reduction of the tool rotational speed below $350 \mathrm{rpm}$ led to the formation of macro-scale defects. The principal directions of the FSP geometry are denoted throughout this study as the welding direction (WD), normal direction (ND) and transverse direction (TD) [11,12].

The microstructures produced by ECAP and FSP were studied by optical microscopy, EBSD and TEM. In the ECAP case, the microstructures were examined in a longitudinal $(P D \times N D)$ section. After FSP, the microstructural observations were performed in a transverse $(T D \times N D)$ section and focused on the stir zone. These section planes are usually used for microstructural observations during ECAP and FSP. As shown below (Fig. 2), all produced microstructures were dominated by nearly equiaxed grains and thus the difference in the section planes hopefully did not affect the microstructure appearance significantly.

The samples for metallographic observations were prepared using conventional polishing techniques followed by etching in Keller's reagent. A suitable surface finish for EBSD and TEM was obtained using electro-polishing in a solution of $25 \%$ nitric acid in ethanol at $-32^{\circ} \mathrm{C}$ and $19.5 \mathrm{~V}$. The EBSD analysis was conducted using a FEI Quanta 600 field-emission-gun scanning electron microscope (FEG-SEM) equipped with TSL OIM ${ }^{\mathrm{TM}}$ software. A $15^{\circ}$ criterion was employed to differentiate low-angle boundaries (LABs) versus high-angle boundaries (HABs). In misorientation maps, the grains are colored according to their orientation relative to the processing directions, with LABs and HABs depicted as white and black lines, respectively. The TEM observations were performed using a JEM-2100EX TEM operating at $200 \mathrm{kV}$. The size of the $\mathrm{Al}_{3} \mathrm{Sc}$ dispersoids was evaluated from TEM micrographs using 1000 individual measurements in each microstructural condition.

To evaluate the mechanical properties of the material with a UFG structure, room-temperature tension tests were conducted using an Instron 5882 universal testing machine. In the equalchannel-angular-pressed (ECAPed) material, the tensile specimens were machined parallel to the pressing direction. In the frictionstir processed (FSPed) material, the tensile specimens were oriented along the welding direction and machined entirely from stir zone material. It is worth noting these orientations of tensile specimens are usually used for examination of mechanical properties of the materials produced by ECAP and FSP. As shown below (Fig. 4), all produced materials were characterized by very weak crystallographic texture and thus should be nearly isotropic. It is believed therefore that the difference in the tensile direction did not significantly influence the mechanical properties. The dimensions of the gage section of the specimens were nominally $25 \mathrm{~mm}$ long, $7 \mathrm{~mm}$ wide and $1.5 \mathrm{~mm}$ thick. The upper and lower surfaces of the tensile specimens were mechanically polished to remove the surface defects and to achieve a uniform thickness. All specimens were tested to failure at a constant crosshead velocity corresponding to a nominal strain rate of $10^{-3} \mathrm{~s}^{-1}$. Two tensile specimens were tested for each material condition.

To assist in the establishment of a microstructure-strength relationship, the shear modulus was also measured using Impulse Excitation Technique (IET) and Resonant Frequency and Damping Analyzer (RFDA) software [19].

\section{Results}

\subsection{Microstructure of initial material}

The microstructure of the initial material is shown in Fig. 1. The grain structure was dominated by coarse grains $\sim 90 \mu \mathrm{m}$ long and approximately $30 \mu \mathrm{m}$ thick, which were elongated in the extrusion direction (Fig. 1a). A minor fraction ( $\sim 4 \mathrm{vol} \%)$ of relatively fine $(\sim 3 \mu \mathrm{m})$ grains was also present along boundaries of the coarse grains (selected area in Fig. 1a). The coarse grains contained a developed substructure (Fig. 1a), and the LAB fraction covered $\sim 75 \%$ of the total grain-boundary area. The mean subgrain intercept measured by EBSD was found to be $4.9 \mu \mathrm{m}$ in the extrusion direction and $4.5 \mu \mathrm{m}$ in transverse direction. The material had a texture consisting of $\{h k l\}\langle 111\rangle$ and $\{h k l\}\langle 100\rangle$ fibers with the peak texture intensity of $\sim 5$ (Fig. 1b). TEM observations revealed a relatively low density of free dislocations $\sim 10^{13} \mathrm{~m}^{-2}$ (Fig. 1c). At high magnifications, homogeneously distributed nano-scale $(\sim 9 \mathrm{~nm})$ precipitates were also seen in the grain interiors (Fig. 1d). These dispersoids often exhibited a characteristic coffee-bean contrast (encircled in Fig. 1d) as well as a cube-on-cube orientation relationship with the aluminum matrix (selected diffraction pattern in the top right corner of Fig. 1d), both reflecting their coherent nature. Thus, the precipitates were interpreted to be $\mathrm{Al}_{3}(\mathrm{Sc}$, $\mathrm{Zr}$ ) dispersoids. A minor fraction of coarser ( $\sim 40 \mathrm{~nm}$ in size) and incoherent $\mathrm{Al}_{6} \mathrm{Mn}$ particles was also found (arrowed in Fig. 1d).

\subsection{Microstructure of processed materials}

\subsubsection{Microstructure morphology and grain size}

The EBSD grain-orientation maps obtained in the processed materials are shown in Fig. 2. The grain-size distributions and other relevant microstructural characteristics derived from the maps are shown in Fig. 3 and Tables 1 \& 2. The produced microstructures were dominated by nearly equiaxed fine grains that were completely delineated by HABs. The material after ECAP, however, also contained a minor fraction of relatively coarse remnants of the original grains with distinct subgrain structure (Fig. 2a, Table 1).

It is clear that ECAP as well as FSP gave rise to drastic grain refinement (Fig. 3, Tables 1 and 2). As expected, the microstructural refinement efficiency somewhat decreased with the ECAP temperature (or tool rotational speed in the case of FSP); this effect was the most pronounced after FSP at $800 \mathrm{rpm}$ (Table 2).

Of particular interest was the observation that the FSPed material generally exhibited a larger grain size than the material subjected to ECAP (Fig. 3, Tables 1 and 2). This indirectly indicates relatively high processing temperatures during FSP.

To the best of the authors' knowledge, the temperatures generated during friction-stirring of $\mathrm{Al}-\mathrm{Mg}$-Sc alloys have not been systematically examined yet. However, the appropriate measurements in AA5059 and AA5083H18 aluminum alloys (which had magnesium content nearly close to that in the studied material 

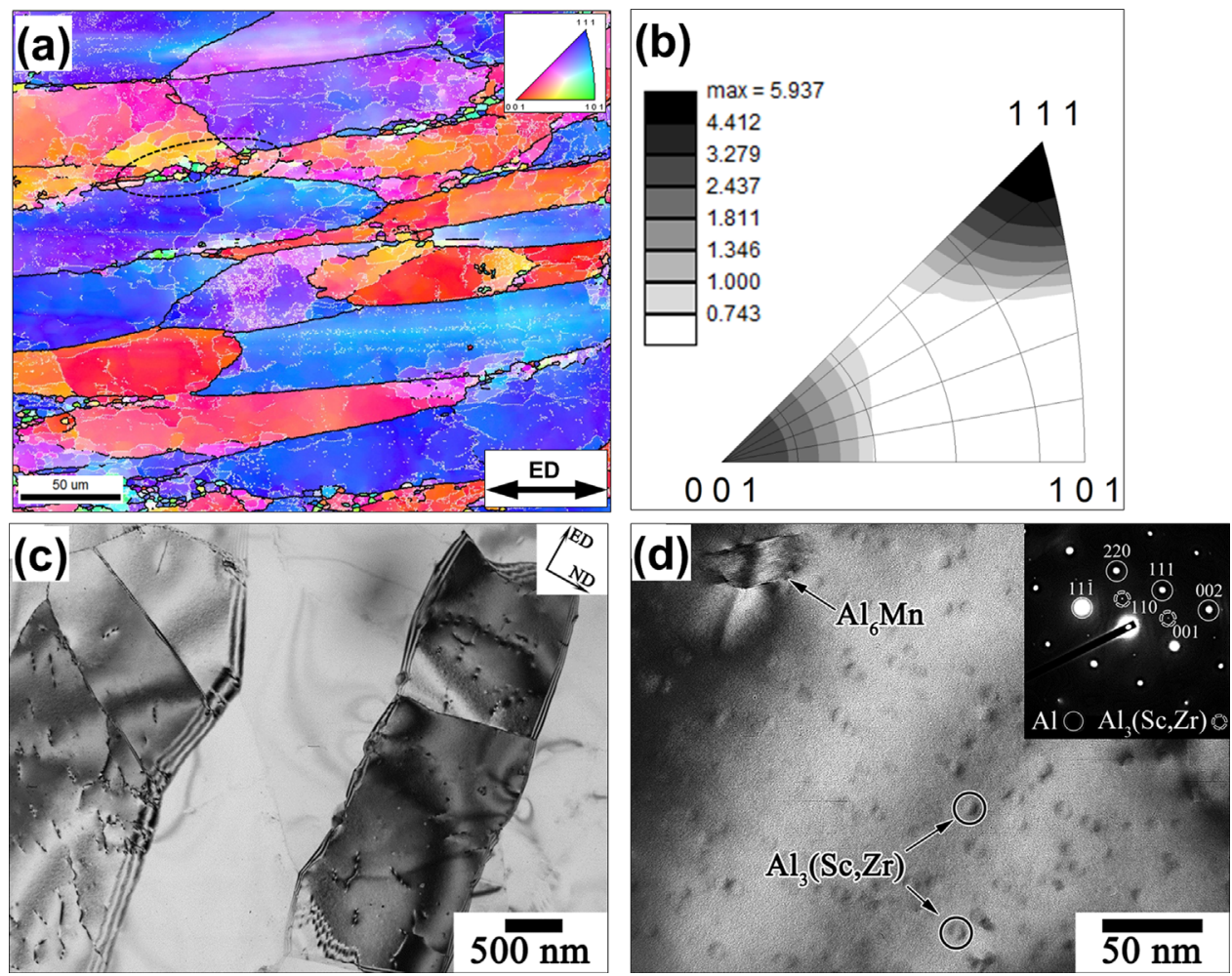

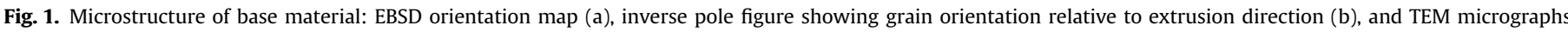

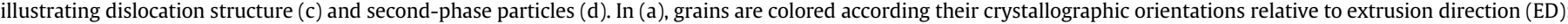

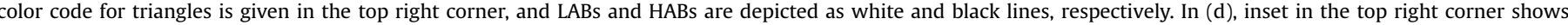
selected area diffraction pattern. (For interpretation of the references to color in this figure legend, the reader is referred to the web version of this article.).
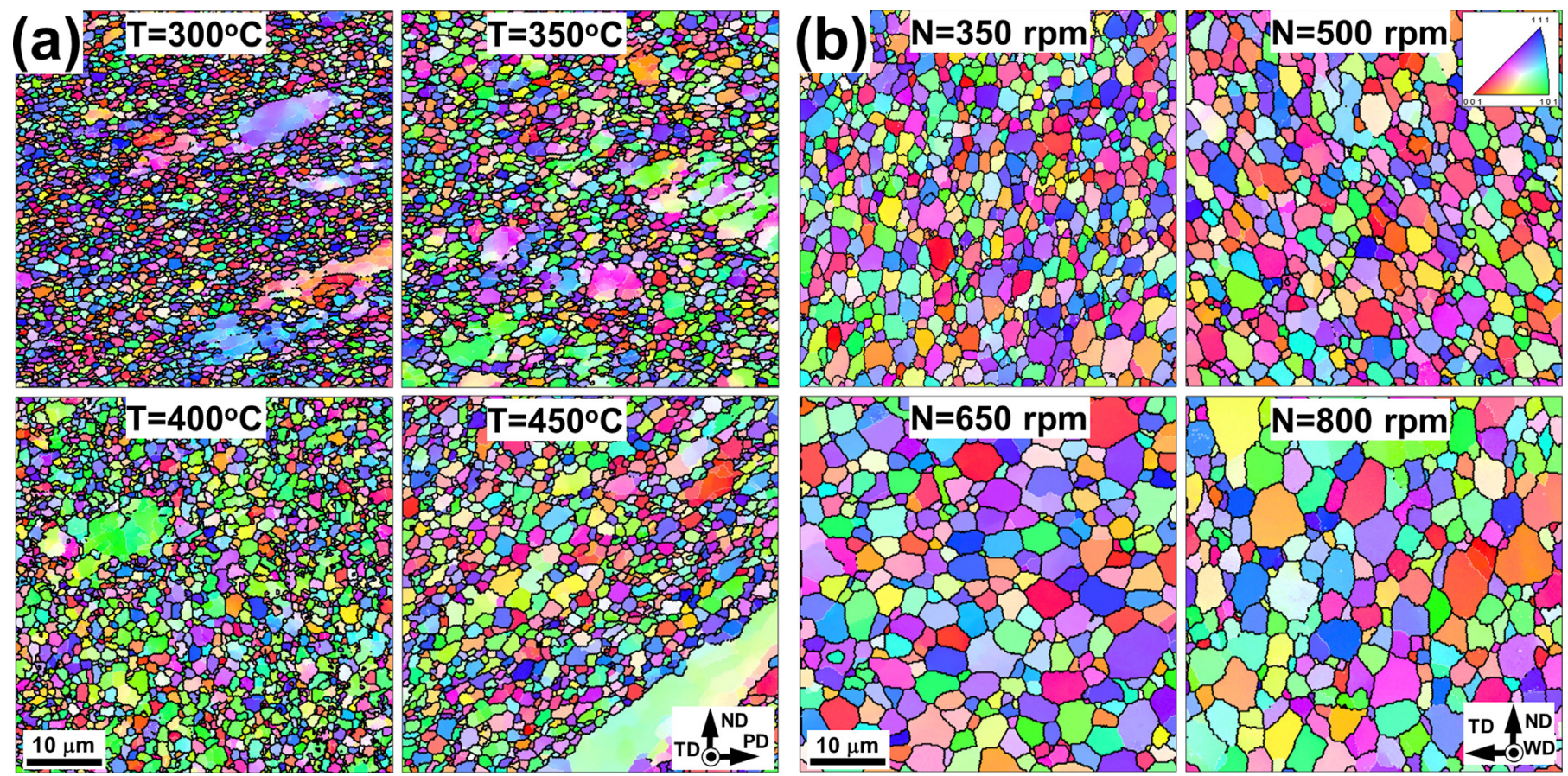

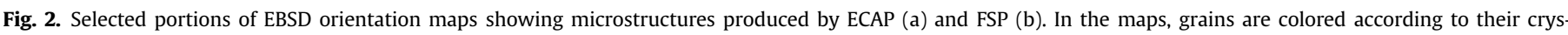

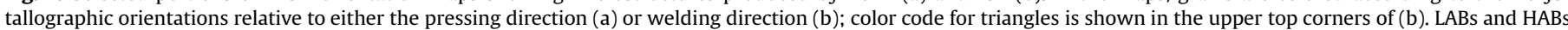

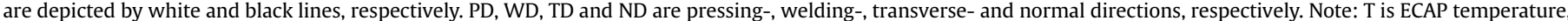
and $\mathrm{N}$ is tool rotational speed during FSP. (For interpretation of the references to color in this figure legend, the reader is referred to the web version of this article.).

and were welded at comparable welding conditions) showed that the peak welding temperature may vary from $400{ }^{\circ} \mathrm{C}$ to $530^{\circ} \mathrm{C}$ depending on the tool rotational speed $[20,21]$.

On the other hand, the difference in grain size between ECAP and FSP may also be attributed to different cooling conditions, i.e. the water quenching after ECAP and air-cooling after FSP. The lower cooling rate after FSP may enhance grain growth and thus promote the coarser grain structure. 
Table 1

Microstructural characteristics of materials subjected to ECAP.

\begin{tabular}{|c|c|c|c|c|c|c|}
\hline \multirow{2}{*}{$\begin{array}{l}\text { ECAP } \\
\text { temperature, }{ }^{\circ} \mathrm{C}\end{array}$} & \multicolumn{2}{|c|}{ Coarse-grained areas } & \multirow{2}{*}{$\begin{array}{l}\text { Mean diameter } \\
\text { of fine grains, } \mu \mathrm{m}\end{array}$} & \multirow{2}{*}{$\begin{array}{l}\text { HAB } \\
\text { fraction, \% }\end{array}$} & \multirow{2}{*}{$\begin{array}{l}\text { Dislocation } \\
\text { density, } \mathbf{m}^{-2}\end{array}$} & \multirow{2}{*}{$\begin{array}{l}\text { Mean diameter of } \\
\mathrm{Al}_{3}(\mathrm{Sc}, \mathrm{Zr}) \text { dispersoids, } \mathrm{nm}\end{array}$} \\
\hline & $\begin{array}{l}\text { Volume } \\
\text { fraction, \% }\end{array}$ & Mean subgrain size, $\mu \mathrm{m}$ & & & & \\
\hline 300 & 10 & 1.1 & 1.2 & 81 & $4 \times 10^{13}$ & 9 \\
\hline 350 & 2 & 1.0 & 1.8 & 84 & $3 \times 10^{13}$ & 9 \\
\hline 400 & 2 & 2.8 & 1.6 & 80 & $1 \times 10^{13}$ & 10 \\
\hline 450 & 6 & 1.9 & 2.4 & 83 & $1 \times 10^{13}$ & 13 \\
\hline
\end{tabular}

Table 2

Microstructural characteristics of materials subjected to FSP.

\begin{tabular}{lllll}
\hline $\begin{array}{l}\text { Tool rota- } \\
\text { tional speed, } \\
\text { rpm }\end{array}$ & $\begin{array}{l}\text { Mean grain } \\
\text { diameter, } \\
\boldsymbol{\mu m}\end{array}$ & $\begin{array}{l}\text { HAB frac- } \\
\text { tion, } \%\end{array}$ & $\begin{array}{l}\text { Dislocation } \\
\text { density, } \mathbf{~ m}^{-2}\end{array}$ & $\begin{array}{l}\text { Mean diameter } \\
\text { of Al }_{\mathbf{3}}(\mathbf{S c}, \mathbf{Z r}) \\
\text { dispersoids, } \mathbf{~ n m ~}\end{array}$ \\
\hline $\mathbf{3 5 0}$ & 2.1 & 86 & $2 \times 10^{13}$ & 16 \\
$\mathbf{5 0 0}$ & 3.4 & 89 & $1 \times 10^{13}$ & 20 \\
$\mathbf{6 5 0}$ & 5.0 & 92 & $1 \times 10^{13}$ & 19 \\
$\mathbf{8 0 0}$ & 7.5 & 81 & $1 \times 10^{13}$ & 27 \\
\hline
\end{tabular}

\subsubsection{Dislocation density and second-phase particles}

Typical TEM images of the processed materials are shown in Fig. 4. The well-annealed structure is evident in all processing conditions. Nevertheless, a relatively high dislocation density was measured after ECAP at 300 and $350{ }^{\circ} \mathrm{C}$ (Table 1). Higher-magnification TEM observations (not shown) revealed the preservation of $\mathrm{Al}_{3}(\mathrm{Sc}, \mathrm{Zr})$ as well as $\mathrm{Al}_{6} \mathrm{Mn}$ particles. The statistics of the $\mathrm{Al}_{3}(\mathrm{Sc}$, $\mathrm{Zr}$ ) particle-size measurements are given in Fig. 5 and Tables 1 and 2. The volume fraction and mean diameter of $\mathrm{Al}_{6} \mathrm{Mn}$ particles are shown in supplementary Table S1.

In the ECAPed material, the particles showed only minor changes in size (Fig. 5a, Table 1). As follows from the coffee-bean contrast as well as the cube-on-cube orientation relationship (not shown), the $\mathrm{Al}_{3}(\mathrm{Sc}, \mathrm{Zr})$ precipitates generally preserved their coherent relationship with the matrix.

This latter observation is consistent with the literature data [22], but nevertheless, it seems to be strange. ECAP introduces very large strains, and thus the particles coherence should be rapidly broken by extensive interaction with dislocations [23-36]. Moreover, the crystallographic orientation of the aluminum matrix during ECAP significantly changed (as shown below), and this should destroy the particle-matrix orientation relationship. Thus, the reason for the preservation of the particle coherence is not clear.

After FSP, a significant coarsening of the $\mathrm{Al}_{3}(\mathrm{Sc}, \mathrm{Zr})$ dispersoids was found (Fig. 5b and Table 2). This effect was the most pronounced in the material produced at the tool rotational speed of $800 \mathrm{rpm}$ (Table 2). In this condition, the particle size exceeded $20 \mathrm{~nm}$, and thus the coherent relationship with the matrix should be lost $[25,26]$. Indeed, the characteristic coffee-bean contrast was typically not observed in this case, though the precipitates still retained the cube-on-cube orientation relationship with the matrix (not shown). The coherence breakdown should abruptly reduce the pinning ability of the $\mathrm{Al}_{3}(\mathrm{Sc}, \mathrm{Zr})$ dispersoids [27] and thus promote the formation of a relatively coarse-grained microstructure in this material condition (Table 2).

Thus, the FSPed material was generally characterized by a relatively low dislocation density and coarser particle size. This supports the above suggestion regarding the relatively high processing temperature and low cooling speed during FSP.

\subsubsection{Texture}

To evaluate material flow during grain refinement, orientation data were derived from EBSD maps and arranged as 111 and 110 pole figures in Figs. 6 and 7. Note that the pole figures were appropriately rotated to align their reference frames with the presumed geometry of simple shear during ECAP and FSP, as discussed in Refs. [27,28].

In all processing conditions, the texture was very weak, with the maximal intensity being below 3 times random. This observation is thought to be associated with interaction of dislocations with the $\mathrm{Al}_{3}(\mathrm{Sc}, \mathrm{Zr})$ dispersoids leading to concentration of slip in micro-shear bands and the respective disturbance of normal texture development [23].

In the ECAPed material, the texture produced at $300{ }^{\circ} \mathrm{C}$ was dominated by the $\{h k l\}\langle 110\rangle$ fiber orientation (Fig. 6a). With the increasing deformation temperature, however, the fiber texture degenerated into $B / \bar{B}\{112\}<110>$ simple-shear orientations (Fig. 6b-d). The reason for this texture transformation is not clear.

In the case of FSP, the evolved textures were irregular and could not be explained in terms of simple shear (Fig. 7). This perhaps reflects the relatively complex character of material flow during FSP as well as higher processing temperatures, as suggested above.

\subsubsection{Misorientation distribution}

Attempting to provide additional insight into the produced fine-grained microstructures, misorientation-angle distributions were derived from the EBSD maps and are shown in Fig. 8. The HAB fractions are shown in Tables 1 and 2.

To evaluate the possible effect of texture on grain boundary development, the so-called "texture-derived" distributions were also calculated and are indicated by solid lines in the figure. In contrast to the measured misorientation distributions displaying the misorientation data between neighboring pixels in an EBSD map, the texture-derived distributions were calculated assuming no spatial correlation between the pixels. In other words, all possible misorientations between the sampled pixels (including noncontiguous ones) were calculated. For comparison, a random misorientation distribution is also shown.

In all cases, the measured- and texture-derived distributions closely resembled the random distribution. This was most likely related to the very weak textures produced in all processing conditions (Figs. 6 and 7).

The ECAPed material was characterized by a relatively low HAB fraction (compare Tables 1 and 2). This is obviously attributable to the incompleteness of the recrystallization process during ECAP, as discussed in Section 3.2.1 (Fig. 2a).

\subsection{Tensile behavior}

To examine the effects of the two studied grain-refinement techniques on the mechanical properties, room-temperature tensile tests were conducted, and the obtained results are summarized in Fig. 9 and Table 3. Duplicate tests showed very similar 

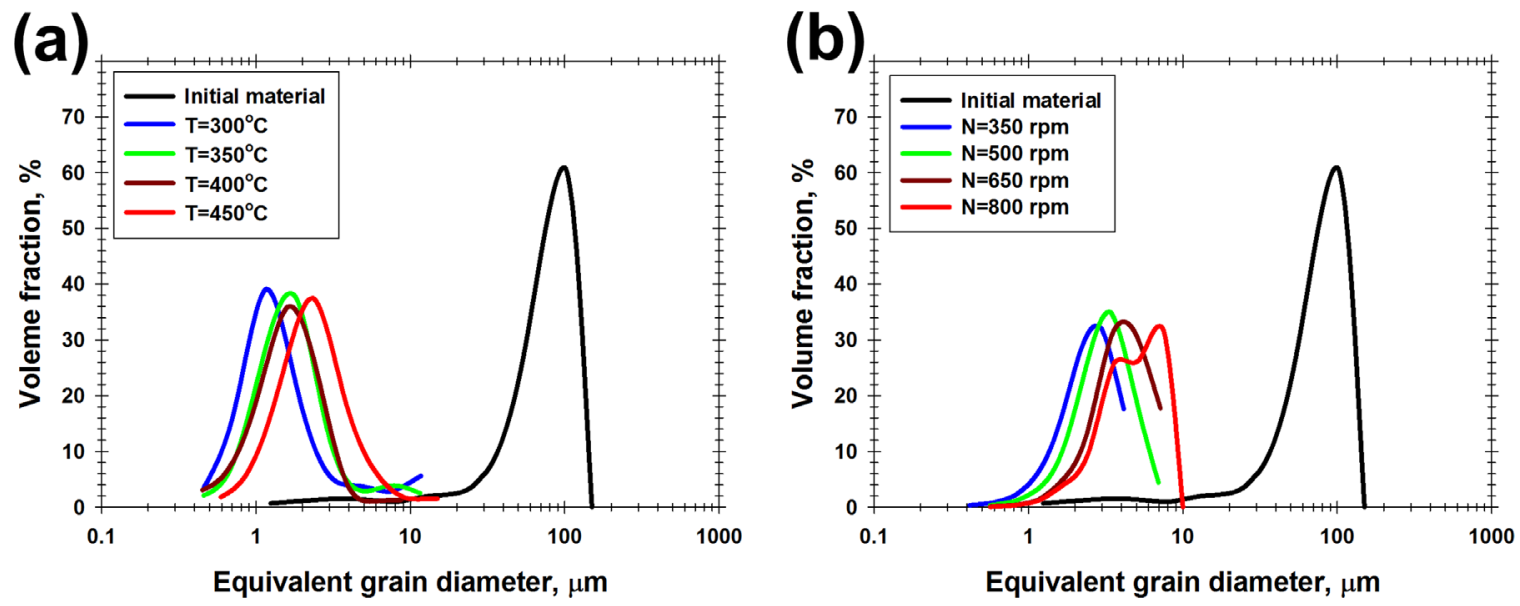

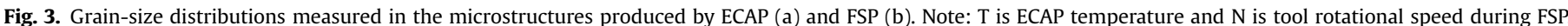
Grain-size distribution for initial material is also shown for comparison.
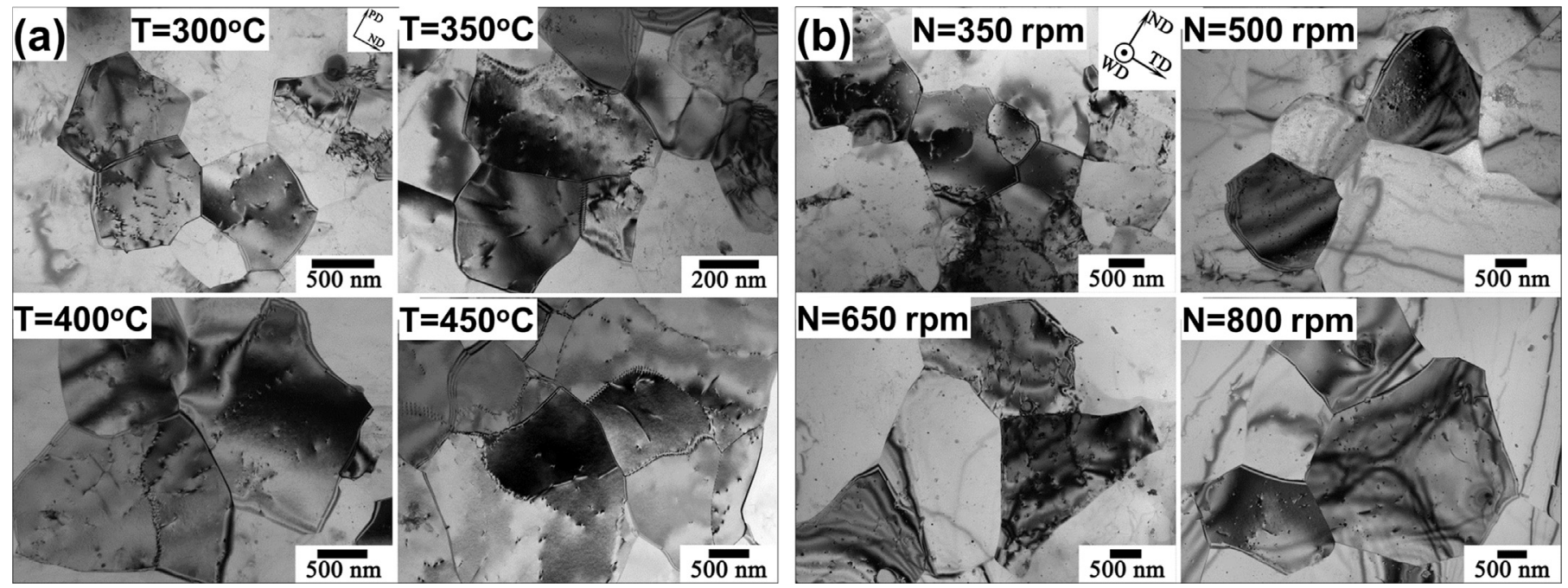

Fig. 4. Typical TEM micrographs showing dislocation structure and second-phase particles in the material produced by ECAP (a) and FSP (b). Note: T is ECAP temperature, and $\mathrm{N}$ is tool rotational speed during FSP.
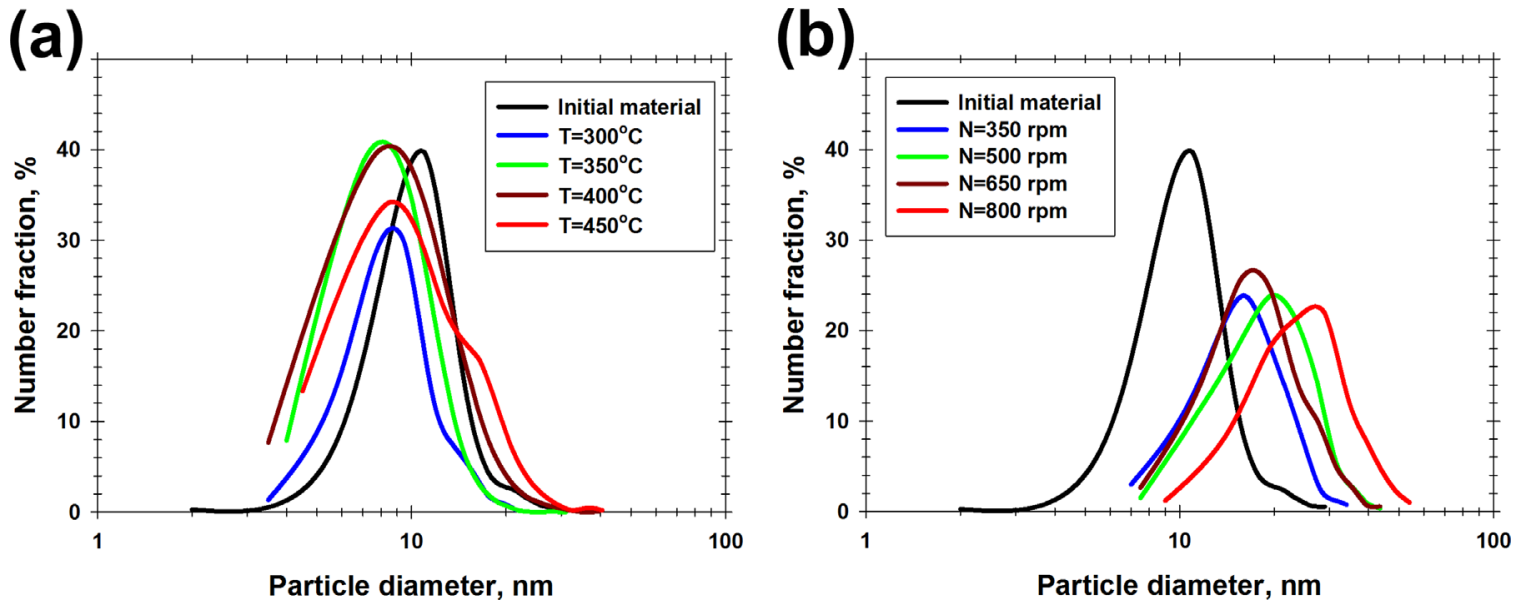

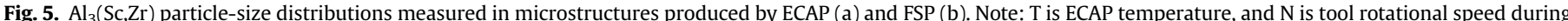
FSP. Particle-size distribution for initial material is also shown for comparison. 

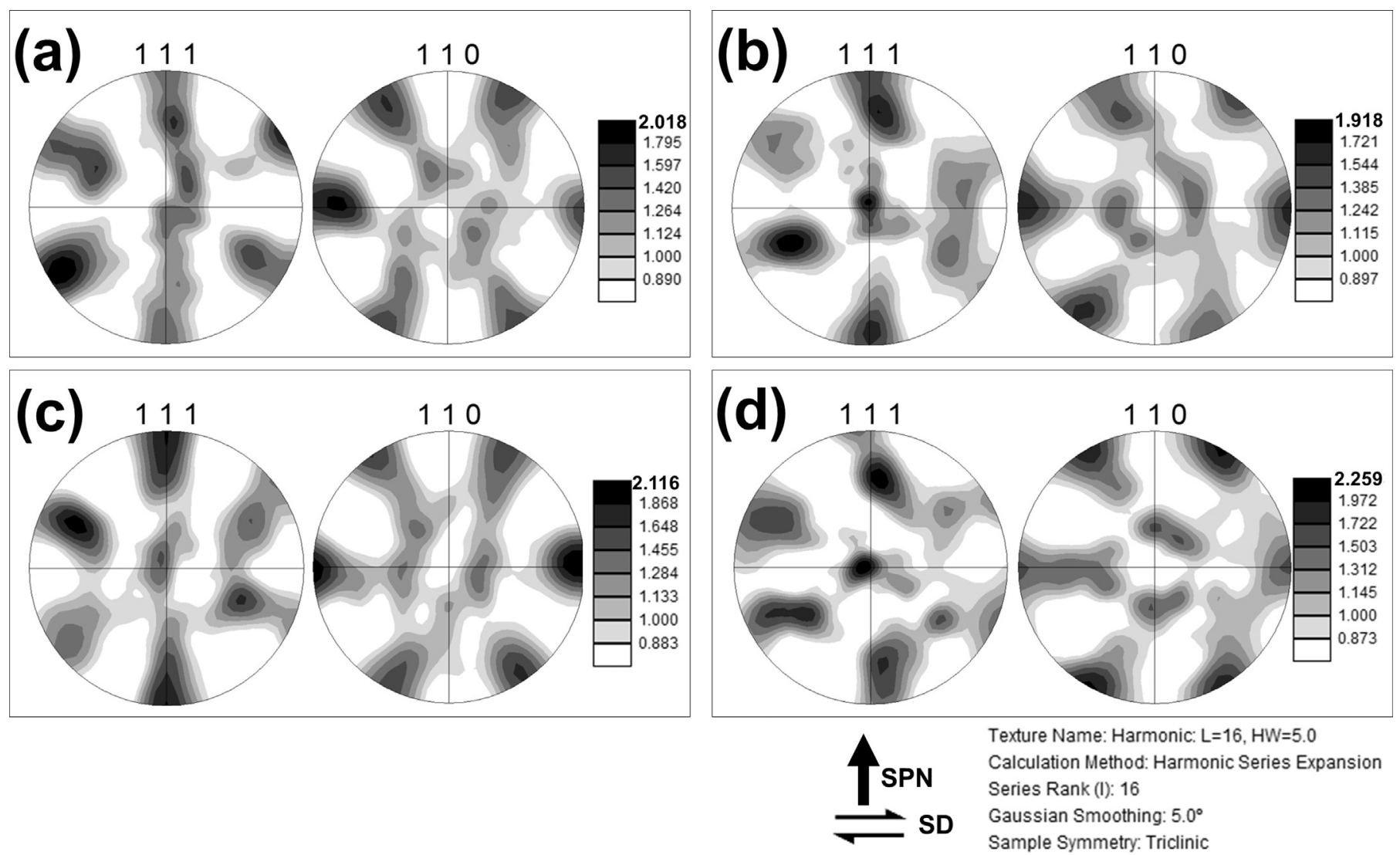

Fig. 6. 111 and 110 pole figures showing texture developed after ECAP at $300{ }^{\circ} \mathrm{C}(\mathrm{a}), 350^{\circ} \mathrm{C}(\mathrm{b}), 400{ }^{\circ} \mathrm{C}(\mathrm{c})$, and $450{ }^{\circ} \mathrm{C}$ (d). Note: The pole figures were appropriately rotated to align their reference frames with a presumed simple-shear geometry; SPN is shear plane normal and SD is shear direction.
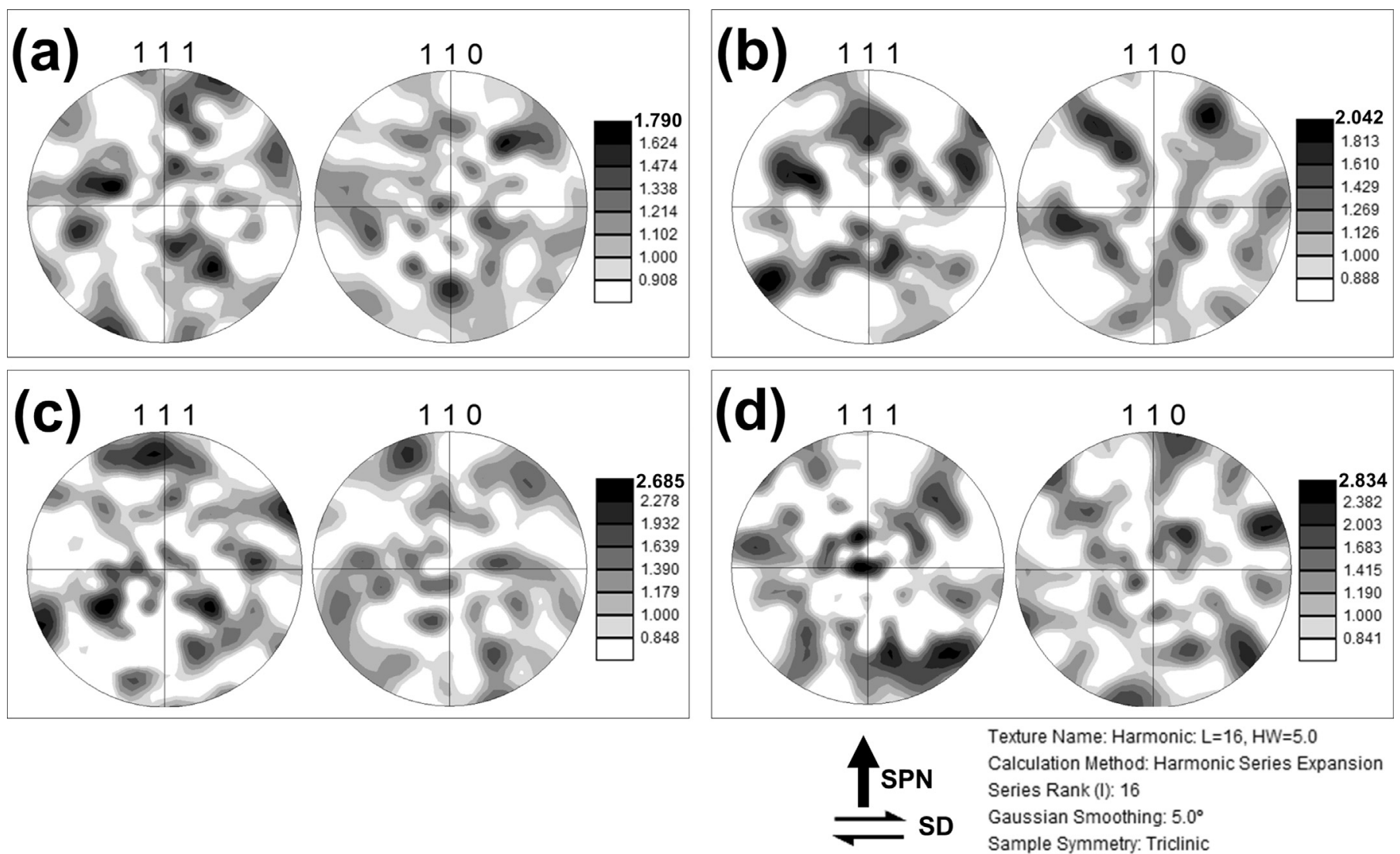

Texture Name: Harmonic: $L=16, H W=5.0$

Calculation Method: Harmonic Series Expansion Series Rank (I): 16

Gaussian Smoothing: $5.0^{\circ}$

Sample Symmetry: Triclinic

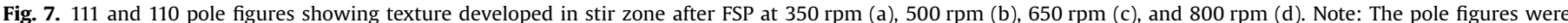
appropriately rotated to align their reference frames with a presumed simple-shear geometry; SPN is shear plane normal and SD is shear direction. 
(a)

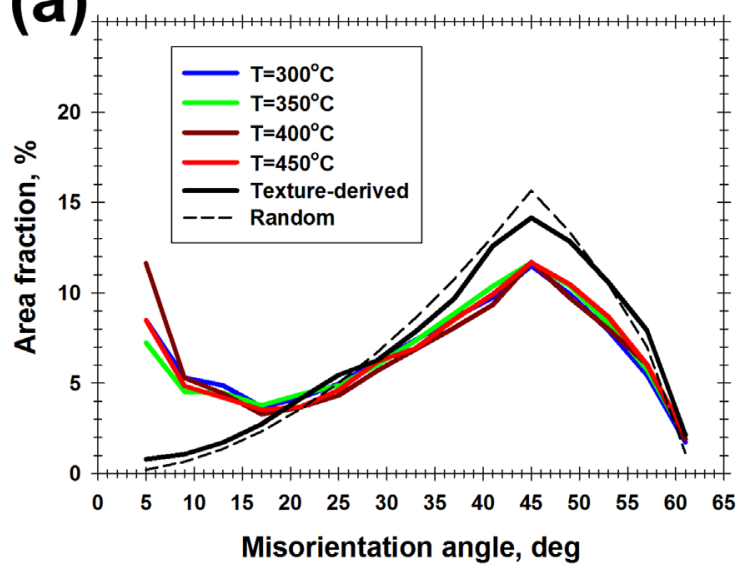

(b)

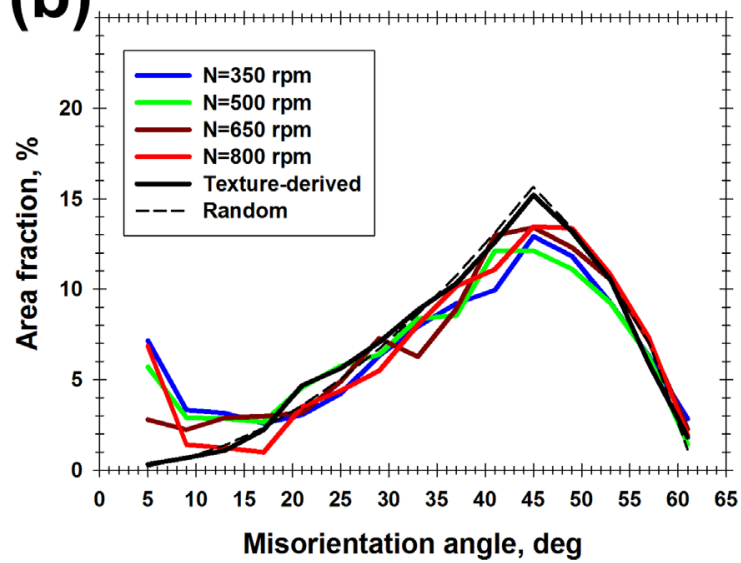

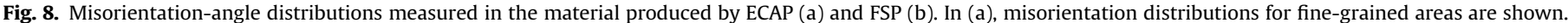
Note: $\mathrm{T}$ is ECAP temperature, and $\mathrm{N}$ is tool rotational speed during FSP.
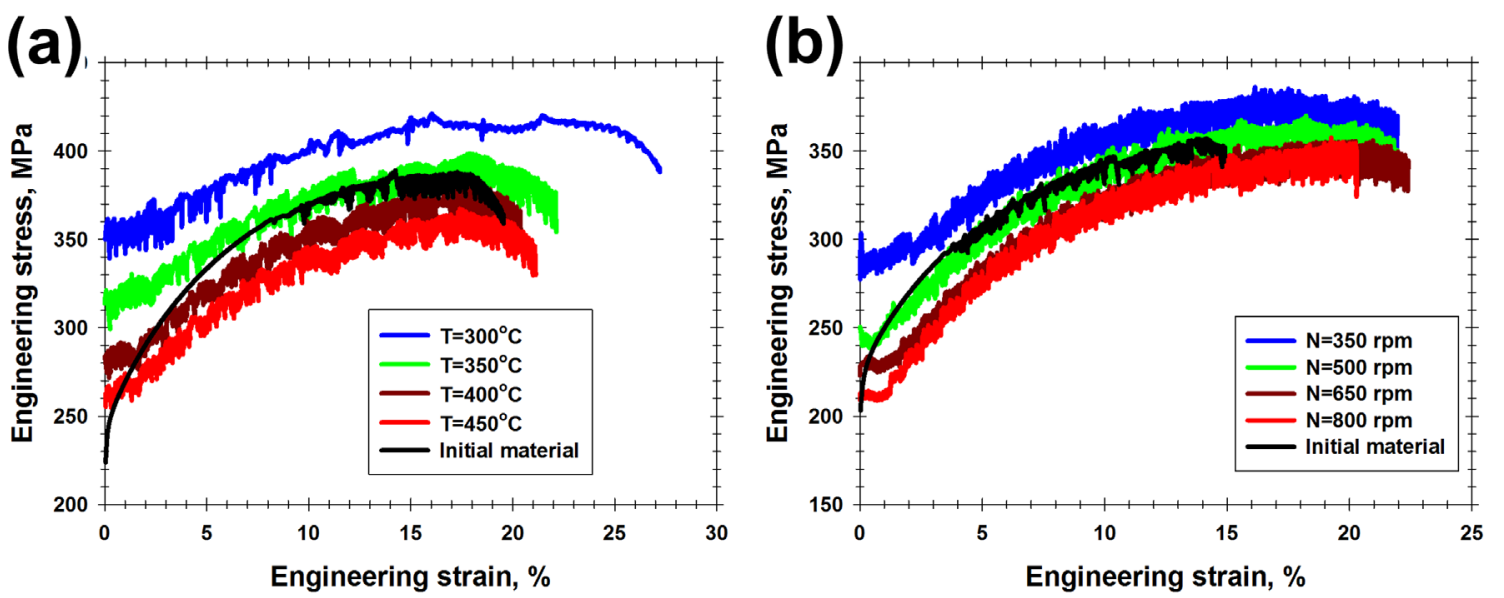

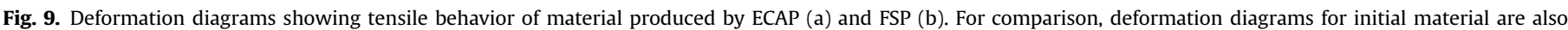

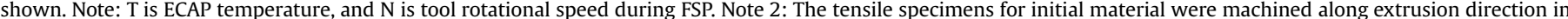
(a) and along transverse direction in (b); i.e. the somewhat different tensile behavior seen in these figures is associated with anisotropy of the initial material.

results; thus, only one set of tensile diagrams is shown in Fig. 9 for each material condition.

In all cases, a significant feature of the deformation diagrams is the repeating oscillations, which indicates the serrated character of the material flow (Fig. 9). In aluminum alloys, this phenomenon is known as the Portevin-Le Chatelier effect, which is conventionally attributed to interactions of dislocations with solute atoms. The serrations are believed to originate from the localization of material flow in deformation bands. The grain refinement significantly reduced the critical strain for the serrations down to the yield point and leads to transition from continuous to discontinuous yielding. A broadly similar effect has been reported in previous works $[29,30]$, but its origin is still unclear.

As expected, ECAP as well as FSP typically imparted a strengthening effect (Fig. 9 and Table 3). It was reduced, however, with the ECAP temperature or with the tool rotational speed during FSP. Moreover, FSP at $800 \mathrm{rpm}$ gave rise to material softening (Table 3).

Depending on the particular processing conditions, the strengthening effects induced by ECAP and FSP were found to overlap (Table 3). Nevertheless, ECAP seems to be more effective than FSP (Table 3). This agrees with the finer grain and dispersoid sizes and higher dislocation density in this processing condition (compare Tables 1 and 2), as discussed above.

\section{Discussion}

\subsection{Strengthening mechanisms}

As shown in Section 3, ECAP as well as FSP led to drastic microstructural changes and related alterations in material properties. In this work, the microstructure-strength relationship is considered in details; to this end, the strengthening mechanisms are discussed in this section. The material ductility is believed to be relatively complex phenomenon which deserves separate investigation and therefore this issue is not analyzed in the present paper.

Assuming that different strengthening mechanisms act independently and thus have additive contributions, the total strength of the studied Al-Mg-Sc alloy may be expressed as [3135]

$\sigma=\sigma_{0}+\sigma_{G B}+\sigma_{S B}+\sigma_{d}+\sigma_{p}$

where $\sigma_{0}$ denotes the threshold strength, $\sigma_{G B}$ is grain boundary strengthening, $\sigma_{S B}$ is subboundary strengthening, $\sigma_{d}$ is dislocation strengthening, and $\sigma_{p}$ is precipitation strengthening.

\subsection{Threshold stress due to solid-solution strengthening}

In Al-Mg alloys (including Al-Mg-Sc alloys), the threshold strength is believed to be dominated by solid-solution 
Table 3

Mechanical properties of initial and processed materials.

\begin{tabular}{|c|c|c|c|c|c|c|c|}
\hline Material condition & YS, MPa & UTS, MPa & $\delta, \%$ & Material condition & YS, MPa & UTS, MPa & $\delta, \%$ \\
\hline \multicolumn{8}{|l|}{ Initial material } \\
\hline Longitudinal direction & 245 & 389 & 20 & Transverse direction & 225 & 357 & 15 \\
\hline ECAP & & & & FSP & & & \\
\hline $\mathrm{T}=300^{\circ} \mathrm{C}$ & 360 & 421 & 28 & $\mathrm{~N}=350 \mathrm{rpm}$ & 304 & 386 & 22 \\
\hline $\mathrm{T}=350^{\circ} \mathrm{C}$ & 320 & 399 & 24 & $\mathrm{~N}=500 \mathrm{rpm}$ & 250 & 370 & 22 \\
\hline $\mathrm{T}=400^{\circ} \mathrm{C}$ & 285 & 381 & 22 & $\mathrm{~N}=650 \mathrm{rpm}$ & 235 & 356 & 22 \\
\hline $\mathrm{T}=450^{\circ} \mathrm{C}$ & 265 & 368 & 23 & $\mathrm{~N}=800 \mathrm{rpm}$ & 215 & 358 & 20 \\
\hline
\end{tabular}

Note: YS, UTS and $\delta$ are yield strength, ultimate tensile strength and elongation-to-failure, respectively.

Table 4

Contributions of strengthening mechanisms.

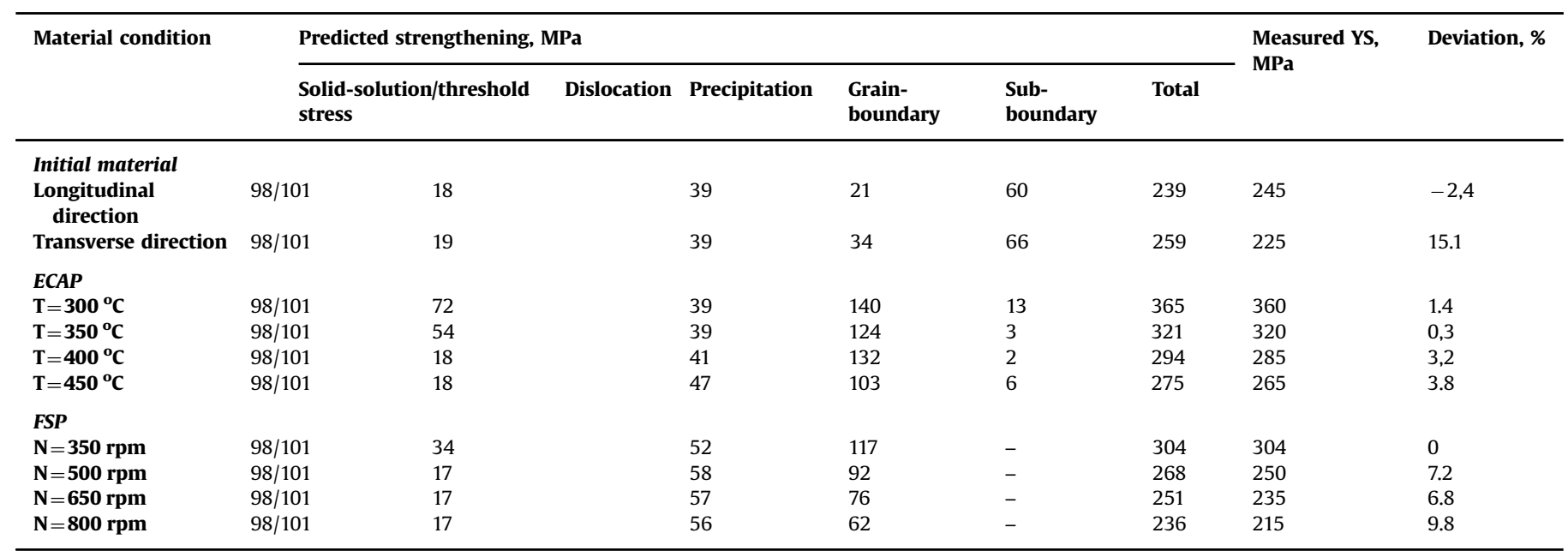

strengthening, which in turn is governed by the magnesium solute content $[32,36]$ :

$\sigma_{S S}=H C^{n}$,

where $H$ is strengthening coefficient, $C$ is magnesium concentration and $n$ is constant.

However, Huskins et al. [34] analyzed the works of Mukai et al. [37] and Ryen et al. [38] in detail and concluded that the additional trace elements (i.e. elements present only in minute amounts), such as $\mathrm{Fe}, \mathrm{Si}, \mathrm{Ti}$ and $\mathrm{Cu}$, also influence the solid solution strengthening. However, in the present alloys, content of these elements is negligible. Moreover, these elements form particles of such compounds as $\mathrm{TiB}_{2}$ and $\mathrm{Al}(\mathrm{Fe}, \mathrm{Mn}) \mathrm{Si}$ during solidification [1]. In the present $\mathrm{Al}-\mathrm{Mg}-\mathrm{Sc}$ alloy, $\mathrm{Mn}$ is an alloying element that may also provide solute strengthening $[34,38]$. Thus, the increment in yield strength due to solid solution strengthening is calculated as [34]

$\sigma_{S S}=\sigma_{\text {trace }}+H_{M g} C_{M g}^{n}+H_{M n} C_{M n}^{m}$,

where $\sigma_{\text {trace }}$ is approximately $24 \mathrm{MPa}$ [34], $H_{M g}=15 \mathrm{MPa} /$ (at. pct $\mathrm{Mg}$ ) [32], $\mathrm{n}=0.75$ for $\mathrm{Al}-\mathrm{Mg}$ alloys [32,38,39], $C_{M g}^{n}$ is the concentration of $\mathrm{Mg}$ in atomic percent, $H_{M n}=18.35 \mathrm{MPa} /($ wt. pct $\mathrm{Mn})^{\mathrm{m}}[31]$, and $\mathrm{m}=0.9$ for Al-Mn alloys [34,38].

From Eq. (3), the solid solution strengthening was calculated to be $89 \mathrm{MPa}$. Taking into account that $\sigma_{\mathrm{o}}$ for $99.99 \%$ pure $\mathrm{Al}$ at ambient temperature is $12 \mathrm{MPa}[34,35,37]$, the threshold strength, $\sigma_{\mathrm{o}}$, for this Al-Mg-Sc alloy is estimated to be approximately $101 \mathrm{MPa}$. Because no clear evidence for the precipitation or dissolution of such second-phase particles as $\mathrm{Al}_{6} \mathrm{Mn}$ and/or $\beta$-phase $\left(\mathrm{Al}_{8} \mathrm{Mg}_{5}\right)$ was found, the threshold strength was considered to be unchanged in all studied material conditions (Table 4).

\subsection{Dislocation strengthening}

The dislocation strengthening is usually described by the classical Taylor relation [40]:

$\sigma_{d}=M \alpha G b \rho^{0.5}$

Here, $M$ is the Taylor factor, $\alpha$ is a constant often valued at 0.24 , Gdenotes the shear modulus, $b$ is the Burgers vector $(0.286 \mathrm{~nm})$, and $\rho$ is the density of free dislocations.

The fine-grained material produced by both ECAP and FSP was characterized by a very weak texture (Figs. $6 \& 7$ ), and thus the Taylor factor was assumed to be 3.1. The initial material, in contrast, had a moderate-strength texture (Fig. 1b). In this case, the average Taylor factor was derived from EBSD data and was found to be 3.1 for the extrusion direction and 3.2 for the transverse direction. Moreover, for the same reason, the shear modulus of the initial material was measured experimentally and found to be 26.6 GPa for the extrusion direction and 27.2 GPa for the transverse direction. In the ECAPed as well as the FSPed materials, the shear modulus was assumed to be $26.9 \mathrm{GPa}$.

The calculated dislocation strengthening is summarized in Table 4.

\subsection{Precipitation strengthening}

In Al-Mg-Sc alloys, precipitation strengthening may be associated either with particle shearing or particle bowing (i.e., Orowan-) mechanisms. The first mechanism is believed to predominate for dispersoid sizes below $\sim 25 \mathrm{~nm}$, whereas the second 
is favored for coarser particles [25,26]. In most material conditions studied in this work, the $\mathrm{Al}_{3}(\mathrm{Sc}, \mathrm{Zr})$ precipitates were typically finer than $25 \mathrm{~nm}$ in diameter (Fig. 5, Tables 1 and 2), and therefore the particle cutting mechanism presumably prevailed.

In this case, the strengthening effect is believed to have resulted primarily from the formation of an anti-phase boundary (APB) within the sheared particle. It may be estimated using the equation [26]

$\sigma_{p}=M \frac{\gamma^{1.5}}{b^{2}}\left(\frac{r f}{G}\right)^{0.5}$

where $\gamma$ denotes the energy required to form the APB, $r$ is the mean particle radius being cut and $f$ is the particle volume fraction.

In Al-Mg-Sc alloys, the APB energy has been reported to vary from 0.1 to $0.67 \mathrm{~J} \mathrm{~m}^{-2}$ depending on the calculation method used [26]. This indicates the fundamental difficulty in accurate determination of the APB energy. In this work, the APB energy was taken to be $0.185 \mathrm{~J} \mathrm{~m}^{-2}$, as recommended by Kendig et al. [26]. It is believed that the difference between the materials studied in the current work and the cited paper is relatively small and therefore the selected magnitude of the APB energy is appropriate. The particle volume fraction was assumed to be $0.1 \%$, based on the measurements reported in our previous work [29].

In the material produced by FSP at a tool rotational speed of $800 \mathrm{rpm}$, the mean $\mathrm{Al}_{3}(\mathrm{Sc}, \mathrm{Zr})$ particle size was measured to exceed $25 \mathrm{~nm}$ (Table 2). In this case, the Orowan mechanism was suggested to control the precipitation strengthening [41]:

$\sigma_{p}=\frac{M G b}{r} f^{0.5}$

The predicted precipitation strengthening is summarized in Table 4.

\subsection{Grain-boundary strengthening}

Grain-boundary strengthening is conventionally described in terms of the well-known Hall-Petch relationship [42,43],

$\sigma_{G B}=k_{H P} d_{G}^{-0.5}$

where $k_{H P}$ is the Hall-Petch constant and $d_{G}$ denotes the mean grain size.

In Al-Mg alloys, the Hall-Petch constant has been reported to vary from 0.15 to 0.26 [31-33]; this highlights the difficulty in the accurate measurement of this value. Considering the similarity of the chemical compositions of the material used in the present work and that studied in Ref. [26], the Hall-Petch constant was taken to be $0.17 \mathrm{MPa} \mathrm{m}^{0.5}$, as suggested by Kendig et al. [26].

The microstructures of the initial as well as ECAPed materials comprised both relatively coarse and relatively fine grains (Figs. 1a and 2a), i.e., they were somewhat bimodal. In this case, the grainboundary strengthening may be described as [44]

$\sigma_{G B}=k_{H P}\left[F d_{C G}^{-0.5}+(1-F) d_{F G}^{-0.5}\right]$

where $F$ is volume fraction of coarse grains (Table 1$), d_{C G}$ is the mean thickness of the coarse grains $(\sim 30 \mu \mathrm{m})$, and $d_{F G}$ is the mean diameter of the fine grains (Table 1 ).

The calculated grain-boundary strengthening is shown in Table 4.

\subsection{Subboundary strengthening}

The initial material contained a developed LAB substructure (Fig. 1a) that may also impart a strengthening effect. In contrast to
HABs, low-angle (i.e., dislocation-) boundaries are assumed to be penetrable for slip and can contribute to strengthening via forest hardening. The strengthening effect of the LABs may therefore be given by $[35,44]$

$\sigma_{S B}=\left(M \alpha G \sqrt{3 b \theta_{L A B}}\right) d_{S G}^{-0.5}$

where $\theta_{L A B}$ is the mean LAB misorientation and $d_{S G}$ denotes the mean subgrain size.

Due to the limited angular resolution of EBSD, boundaries with misorientation below $2^{\circ}$ could not be reliably detected, and thus the $\theta_{L A B}$ parameter could not be simply derived from EBSD data. On the other hand, there is significant scattering in the scientific literature in the measurements of the mean LAB misorientation in heavily deformed aluminum. This scatter is most likely attributable to the co-existence of two different types of LABs (i.e., incidental dislocation boundaries and geometrically necessary boundaries), which accumulate misorientation at different rates. Nevertheless, a magnitude of $2-3^{\circ}$ is sometimes reported as a reasonable mean misorientation, e.g., Refs. $[29,33,45,46]$. In this work, therefore, $\theta_{L A B}$ was accepted to be $3^{\circ}$ (or 0.052 rad).

In the ECAPed material, the LABs were preferentially clustered in the retained coarse-grained areas (Fig. 2a). Thus, the respective strengthening effect could be estimated as

$\sigma_{S B}=F\left(M \alpha G \sqrt{3 b \theta_{L A B}}\right) d_{S G}^{-0.5}$

The predicted subboundary strengthening is summarized in Table 4.

\subsection{Strengthening efficiencies of ECAP and FSP}

The contributions of different strengthening mechanisms to the final yield strength in all studied conditions are summarized in Table 4 . With the exception of the initial material tensioned in the transverse direction, the deviation between the predicted and measured strengths does not exceed $10 \%$, thus being relatively low. Taking into account the uncertainty of many parameters used in the calculations (particularly the magnitude of $\theta_{L A B}$ ), this accuracy is believed to be acceptable.

As follows from Table 4, the material strengthening induced by ECAP as well as FSP was primarily related to the grain refinement. At relatively low ECAP temperatures, a high dislocation density may also substantially contribute to the yield strength. Moreover, the subtle coarsening of $\mathrm{Al}_{3}(\mathrm{Sc}, \mathrm{Zr})$ dispersoids observed at relatively high deformation temperatures also promoted material strengthening due to the enlargement of the particle cutting stresses. However, the potential of this mechanism was limited due to the coherency lost at precipitate sizes above $25 \mathrm{~nm}$, as observed in the material FSPed at $800 \mathrm{rpm}$. However, Sauvage et al. have shown that $\mathrm{Al}_{3}(\mathrm{Sc}, \mathrm{Zr})$ dispersoids remain unchanged during friction stir welding (FSW) [18].

Thus, the relatively high strengthening efficiency of ECAP was mainly associated with the finer grain size and higher dislocation density.

\section{Conclusions}

In this work, the efficiencies of ECAP and FSP for grain refinement in an Al-Mg-Sc alloy were compared with each other. To this end, several ECAP and FSP trials were performed over a wide temperature range, and the produced microstructures were quantified using EBSD and TEM. The main conclusions for this work are as follows.

In contrast to ECAP, the fine-grained material produced by FSP was found to be completely recrystallized and characterized by a 
coarser grain and particle size, lower dislocation density, more irregular texture, higher HAB fraction and lower strength.

Based on a detailed microstructural examination, the strengthening mechanisms contributing to the room temperature yield strength were quantified. In all cases, the strengthening effect was shown to be primarily related to grain refinement. At relatively low ECAP temperatures, the high dislocation density may also substantially contribute to the material strength. Moreover, the subtle coarsening of the $\mathrm{Al}_{3}(\mathrm{Sc}, \mathrm{Zr})$ dispersoids observed at relatively high deformation temperatures also imparted a strengthening effect due to the enlargement of the particle cutting stresses. However, the potential of the latter mechanism was limited due to the coherency lost at precipitate sizes exceeding $25 \mathrm{~nm}$ and the respective activation of the Orowan bowing mechanism.

Generally, the grain refinement efficiency of FSP was lower than that of ECAP. Based on microstructural observations, this result may be explained in terms of relatively high processing temperature and low cooling speed associated with FSP. Considering preservation of the $\mathrm{Al}_{3}(\mathrm{Sc}, \mathrm{Zr})$ dispersoids which can efficiently pin grain-boundary migration, the cooling effect is expected to be low; therefore, the high processing temperature is believed to be the primary factor. This issue, however, requires further study.

\section{Acknowledgments}

The financial support received from the Ministry of Education and Science, Russia, under Grant No. 14.578.21.0097 (ID number RFMEFI57814X0097) is gratefully acknowledged. The authors are grateful to the personnel of the Joint Research Centre, Belgorod State University, for their assistance with the instrumental analysis.

\section{Appendix A. Supplementary material}

Supplementary data associated with this article can be found in the online version at http://dx.doi.org/10.1016/j.msea.2016.08.021.

\section{References}

[1] I.J. Polmear, Light Alloys: From Traditional Alloys to Nanocrystals, 4th ed., Butterworth-Heinemann//Elsevier, UK, 2006.

[2] J. Røyset, N. Ryum, Scandium in aluminium alloys, Inter. Mater. Rev. 50 (2005) 19-44, http://dx.doi.org/10.1179/174328005X14311.

[3] R.Z. Valiev, T.G. Langdon, Principles of equal-channel angular pressing as a processing tool for grain refinement, Prog. Mater. Sci. 51 (2006) 881-981, http: //dx.doi.org/10.1016/j.pmatsci.2006.02.003.

[4] Y. Estrin, A. Vinogradov, Extreme grain refinement by severe plastic deformation: a wealth of challenging science, Acta Mater. 61 (2013) 782-817, http://dx.doi.org/10.1016/j.actamat.2012.10.038.

[5] S. Komura, M. Furukawa, Z. Horita, M. Nemoto, T.G. Langdon, Optimizing the procedure of equal-channel angular pressing for maximum superplasticity, Mater. Sci. Eng. A 297 (2001) 111-118, http://dx.doi.org/10.1016/S0921-5093 (00)01255-7.

[6] Z. Horita, M. Furukawa, M. Nemoto, A.J. Barnes, T.G. Langdon, Superplastic forming at high strain rates after severe plastic deformation, Acta Mater. 48 (2000) 3633-3640, http://dx.doi.org/10.1016/S1359-6454(00)00182-8.

[7] S. Lee, A. Utsunomiya, H. Akamatsu, K. Neishi, M. Furukawa, Z. Horita, T. G. Langdon, Influence of scandium and zirconium on grain stability and superplastic ductility in ultrafine-grained Al-Mg alloys, Acta Mater. 50 (2002) 553-564, http://dx.doi.org/10.1016/S1359-6454(01)00368-8.

[8] F. Musin, R. Kaibyshev, Y. Motohashi, G. Itoh, High strain rate superplasticity in a commercial Al-Mg-Sc alloy, Scr. Mater. 50 (2004) 511-516, http://dx.doi.org/ 10.1016/j.scriptamat.2003.10.021.

[9] A. Vinogradov, A. Washikita, K. Kitagawa, V.I. Kopylov, Fatigue life of fine-grain Al-Mg-Sc alloys produced by equal-channel angular pressing, Mater. Sci. Eng. A 349 (2003) 318-326, http://dx.doi.org/10.1016/S0921-5093(02)00813-4.

[10] R.S. Mishra, M.W. Mahoney, S.X. McFadden, N.A. Mara, A.K. Mukherjee, High strain rate superplasticity in a friction stir processed $7075 \mathrm{Al}$ alloy, Scr. Mater. 42 (2000) 163-168, http://dx.doi.org/10.1016/S1359-6462(99)00329-2.

[11] R.S. Mishra, Z.Y. Ma, Friction stir welding and processing, Mater. Sci. Eng. R. 50 (2005) 1-78, http://dx.doi.org/10.1016/j.mser.2005.07.001.

[12] P.L. Threadgill, A.J. Leonard, H.R. Shercliff, P.J. Withers, Friction stir welding of aluminium alloys, Int. Mater. Rev. 54 (2009) 49-93, http://dx.doi.org/10.1179/ $174328009 \times 411136$

[13] I. Charit, R.S. Mishra, Low temperature superplasticity in a friction-stir-processed ultrafine grained Al-Zn-Mg-Sc alloy, Acta Mater. 53 (2005) 4211-4223, http://dx.doi.org/10.1016/j.actamat.2005.05.021.

[14] N. Kumar, R.S. Mishra, C.S. Huskamp, K.K. Sankaran, Microstructure and mechanical behavior of friction stir processed ultrafine grained Al-Mg-Sc alloy, Mater. Sci. Eng. A 528 (2011) 5883-5887, http://dx.doi.org/10.1016/j. msea.2011.03.109.

[15] F.C. Liu, Z.Y. Ma, F.C. Zhang, High strain rate superplasticity in a micro-grained Al-Mg-Sc alloy with predominant high angle grain boundaries, J. Mater. Sci. Technol. 28 (11) (2012) 1025-1030, http://dx.doi.org/10.1016/S1005-0302(12) 60168-6.

[16] F.C. Liu, Z.Y. Ma, L.Q. Chen, Low-temperature superplasticity of Al-Mg-Sc alloy produced by friction stir processing, Scr. Mater. 60 (2009) 968-971, http://dx. doi.org/10.1016/j.scriptamat.2009.02.021.

[17] F.C. Liu, Z.Y. Ma, Achieving exceptionally high superplasticity at high strain rates in a micrograined $\mathrm{Al}-\mathrm{Mg}-\mathrm{Sc}$ alloy produced by friction stir processing, Scr. Mater. 59 (2008) 882-885, http://dx.doi.org/10.1016/j. scriptamat.2008.06.035.

[18] X. Sauvage, A. Dede, A. Munoz, B. Huneau, Precipitate stability and recrystallisation in the weld nuggets of friction stir welded $\mathrm{Al}-\mathrm{Mg}-\mathrm{Si}$ and $\mathrm{Al}-$ Mg-Sc alloys, Mater. Sci. Eng. A 491 (2008) 346-371, http://dx.doi.org/10.1016/ j.msea.2008.02.006.

[19] O. Bahr, P. Schaumann, B. Bollen, J. Bracke, Young's modulus and Poisson's ratio of concrete at high temperatures: Experimental investigations, Mater. Des. 45 (2013) 421-429, http://dx.doi.org/10.1016/j.matdes.2012.07.070.

[20] H. Izadi, R. Sandstrom, A.P. Gerlich, Growth Behavior and Hall-Petch Strengthening in Friction Stir Processed Al 5059, Metall. Mater. Trans. A 45 (2014) 5635-5644, http://dx.doi.org/10.1007/s11661-014-2492-x.

[21] D. Kim, H. Badarinarayan, J.H. Kim, Ch Kim, K. Okamoto, R.H. Wagoner, K. Chung, Numerical simulation of friction stir butt welding process for AA5083-H18 sheets, Eur. J. Mech. A: Solids 29 (2010) 204-215, http://dx.doi. org/10.1016/j.euromechsol.2009.10.006.

[22] O. Sitdikov, T. Sakai, E. Avtokratova, R. Kaibyshev, K. Tsuzaki, Y. Watanabe, Microstructure behavior of Al-Mg-Sc alloy processed by ECAP at elevated temperature, Acta Mater. 56 (2008) 821-834, http://dx.doi.org/10.1016/j. actamat.2007.10.029.

[23] F.J. Humphreys, M. Hatherly, Recrystallization and Related Phenomena, Elsevier, Oxford 2004, p. 574, http://dx.doi.org/10.1002/maco.19970480915.

[24] M. Schobel, P. Pongratz, H.P. Degischer, Coherency loss of $\mathrm{Al}_{3}(\mathrm{Sc}, \mathrm{Zr})$ precipitates by deformation of an Al-Zn-Mg alloy, Acta Mater. 60 (2012) 4247-4254, http://dx.doi.org/10.1016/j.actamat.2012.04.011.

[25] M.J. Jones, F.J. Humphreys, Interaction of recrystallization and precipitation: The effect of $\mathrm{Al}_{3} \mathrm{Sc}$ on the recrystallization behaviour of deformed aluminium, Acta Mater. 51 (2003) 2149-2159, http://dx.doi.org/10.1016/S1359-6454(03) 00002-8

[26] K.L. Kendig, D.B. Miracle, Strengthening mechanisms of an Al-Mg-Sc-Zr alloy, Acta Mater. 50 (2002) 4165-4175, http://dx.doi.org/10.1016/S1359-6454(02) 00258-6.

[27] R.W. Fonda, K.E. Knipling, Texture development in friction stir welds, Sci. Technol. Weld. Join. 16 (2001) 288-294, http://dx.doi.org/10.1179/ 1362171811Y.0000000010.

[28] S. Li, I.R. Beyerlein, M.A.M. Bouke, Texture formation during equal channel angular extrusion of fcc and bcc materials: comparison with simple shear, Mater. Sci. Eng. A 394 (2005) 66-77, http://dx.doi.org/10.1016/j. msea.2004.11.032.

[29] S. Malopheyev, V. Kulitskiy, S. Mironov, D. Zhemchuzhnikova, R. Kaibyshev, Friction-stir welding of an $\mathrm{Al}-\mathrm{Mg}-\mathrm{Sc}-\mathrm{Zr}$ alloy in as-fabricated and work-hardened conditions, Mater. Sci. Eng. A 600 (2014) 159-170, http://dx.doi.org/ 10.1016/j.msea.2014.02.018.

[30] A. Mogucheva, D. Yuzbekova, R. Kaibyshev, T. Lebedkina, M. Lebedkin, Effect of grain refinement on jerky flow in Al-Mg-Sc alloy, Metall. Mater. Trans. A 47 (2016) 2093-2106, http://dx.doi.org/10.1007/s11661-016-3381-2.

[31] B.O. Han, F.A. Mohamed, Z. Lee, S.R. Nutt, E.J. Lavernia, Mechanical properties of an ultrafine-grained Al-7.5 pct Mg alloy, Metall. Mater. Trans. A 34 (2003) 603-613, http://dx.doi.org/10.1007/s11661-003-0095-z.

[32] T.J. Harrell, T.D. Topping, H. Wen, T. HU, J.M. Schoenung, E.J. Lavernia, Strengthening mechanisms in an ultrafine grained Al-Mg-Sc alloy produced by powder metallurgy, Metall. Mater. Trans. A (2014), http://dx.doi.org/ 10.1007/s11661-014-2569-6.

[33] S. Malopheyev, R. Kaibyshev, Strengthening mechanisms in a Zr-modified 5083 alloy deformed to high strains, Mater. Sci. Eng. A 620 (2014) 246-252, http://dx.doi.org/10.1016/j.msea.2014.10.030.

[34] E.L. Huskins, Strengthening mechanisms in an Al-Mg alloy, Mater. Sci. Eng. A 527 (2010) 1292-1298, http://dx.doi.org/10.1016/j.msea.2009.11.056.

[35] N. Kamikawa, X. Huang, N. Tsuji, N. Hansen, Strengthening mechanisms in nanostructured high-purity aluminium deformed to high strain and annealed, Acta Mater. 57 (2009) 4198-4208, http://dx.doi.org/10.1016/j. actamat.2009.05.017.

[36] R.W. Cahn, P. Haasen, Physical Metallurgy, 4th ed., North-Holland Physics, 
Amsterdam, 1996.

[37] T. Mukai, K. Higashi, S. Tanimura, Mater. Sci. Eng. A 176 (1994) 181-189, http: //dx.doi.org/10.1016/0921-5093(94)90974-1.

[38] Ø. Ryen, O. Nijs, E. Sjolander, B. Holmedal, H.-E. Ekstrom, E. Nes, Metall. Mater. Trans. A 37 (2006) 1999-2006.

[39] O.D. Sherby, R.A. Anderson, J.E. Dorn, J. Met. 189 (1951) 643-652.

[40] G.I. Taylor, Plastic strain in metals, J. Inst. Met. 62 (1938) 307-324.

[41] E. Orowan, Symposium on internal stresses. In: Metals and alloys, Session III Discussion, London: Institute of Metals, 1948.

[42] E.O. Hall, The deformation and aging of mild steel: III Discussion of results, Proc. Phys. Soc. Lond. 64 (1951) 747-753, http://dx.doi.org/10.1088/0370-1301/ $64 / 9 / 303$.
[43] N.J. Petch, The cleavage strength of polycrystals, J. Iron Steel Inst. Lond. 173 (1953) 25-28.

[44] N. Hansen, Hall-Petch relation and boundary strengthening, Scr. Mater. 51 (2004) 801-806, http://dx.doi.org/10.1016/j.scriptamat.2004.06.002.

[45] P.J. Hurley, F.J. Humphreys, The application of EBSD to the study of substructural development in a cold rolled single-phase aluminium alloy, Acta Mater. 51 (2003) 1087-1102, http://dx.doi.org/10.1016/S1359-6454(02) 00513-X.

[46] Q. Liu, X. Huang, D.J. Lloyd, N. Hansen, Microstructure and strength of commercial purity aluminium (AA 1200) cold-rolled to large strains, Acta Mater. 50 (2002) 3789-3802, http://dx.doi.org/10.1016/S1359-6454(02)00174-X. 